\title{
Migraine-like visual aura: Can it be an early-onset symptom of astrocytoma?
}

\author{
Migren benzeri görsel aura: Astrositomalı hastalarda erken bir başlangıç bulgusu \\ olabilir mi?
}

(1) Gökhan EVCiLi, (1) Muhammed Nur ÖĞÜN, (1) Uygar UTKU

\begin{abstract}
Summary
Photopsia, fortification spectra, and the slow propagation of a scintillating scotoma across the visual field are typical diagnostic features of the visual aura of migraine. In the vast majority of cases, the diagnosis can be made without the need for further investigations. Herein, we report three consecutive cases with an astrocytoma and discuss clinical features of migraine-like visual aura.

Keywords: Astrocytoma; migraine like visual aura.

Özet

Görme alanında fotopsi, fortifikasyon spektrumu ve parlama skotomu, görsel auralı migrenin karakteristik tanısal özellikleridir. Olguların büyük bir çoğunluğunda tanı ileri tetkiklere gerek kalmaksızın yapılabilmektedir. Bu makalede, astrositomlu üç ardışık olgu sunuldu ve migren benzeri görsel auranın klinik özellikleri tartışıldı.

Anahtar sözcükler: Astrositoma; migren benzeri görsel aura.
\end{abstract}

\section{Introduction}

Photopsia, fortification spectra, and the slow propagation of a scintillating scotoma across the visual field are typical diagnostic features of the visual aura of migraine. In the vast majority of cases, the diagnosis can be made without the need for further investigations. ${ }^{[1]}$ Typical migraine-like visual aura due to a structural lesion with the absence of other neurological signs or symptoms is rare. ${ }^{[2,3]}$ Herein, we report three consecutive cases with an astrocytoma and discuss clinical features of migraine-like visual aura in the light of the literature data.

\section{Case Reports}

Case-1: A 32-year-old male was admitted with a two-year history of migraine headache-associated with visual aura. He suffered from gradually increasing in frequency of headache and changing in the characteristics of visual aura for two months. The patient described the visual aura as repetitive flashes of light every five seconds and lasting approximately two minutes in the right visual field. He experienced five to 15 episodes in this period and several minutes later by a moderate to severe right-sided throbbing headache. There were no identifiable triggers for these attacks. There was also associated nausea, vomiting, phonophobia or photophobia. He had no other neurological or ophthalmological symptoms. His physical, neurological, and fundoscopic examination findings, including blood pressure and meningeal signs, were normal. Complete blood count and routine biochemistry results, including liver and renal function tests and erythrocyte sedimentation rate, were normal. Electroencephalography (EEG) revealed normal findings. Cranial magnetic resonance imaging (MRI) revealed a lesion without any contrast enhancement within the right frontal lobe, consistent with a low-grade astrocytoma (Fig. 1). Stereotactic biopsy was, then, performed. The biopsy result was consistent with a low-grade astrocytoma. 


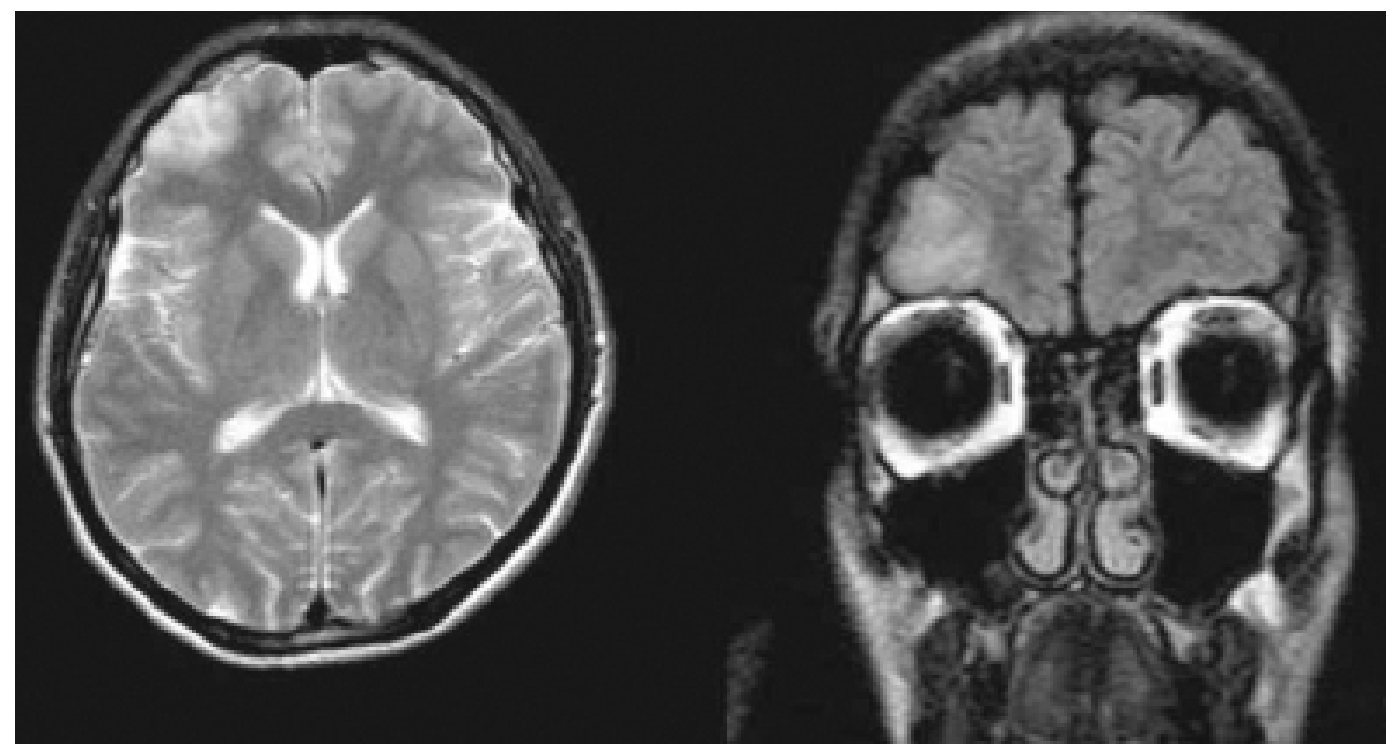

Figure 1. T2-weighted, axial, and fluid-attenuated inversion recovery coronal magnetic resonance imaging scans showing a well-defined focal mass lesion in the right frontal lobe.

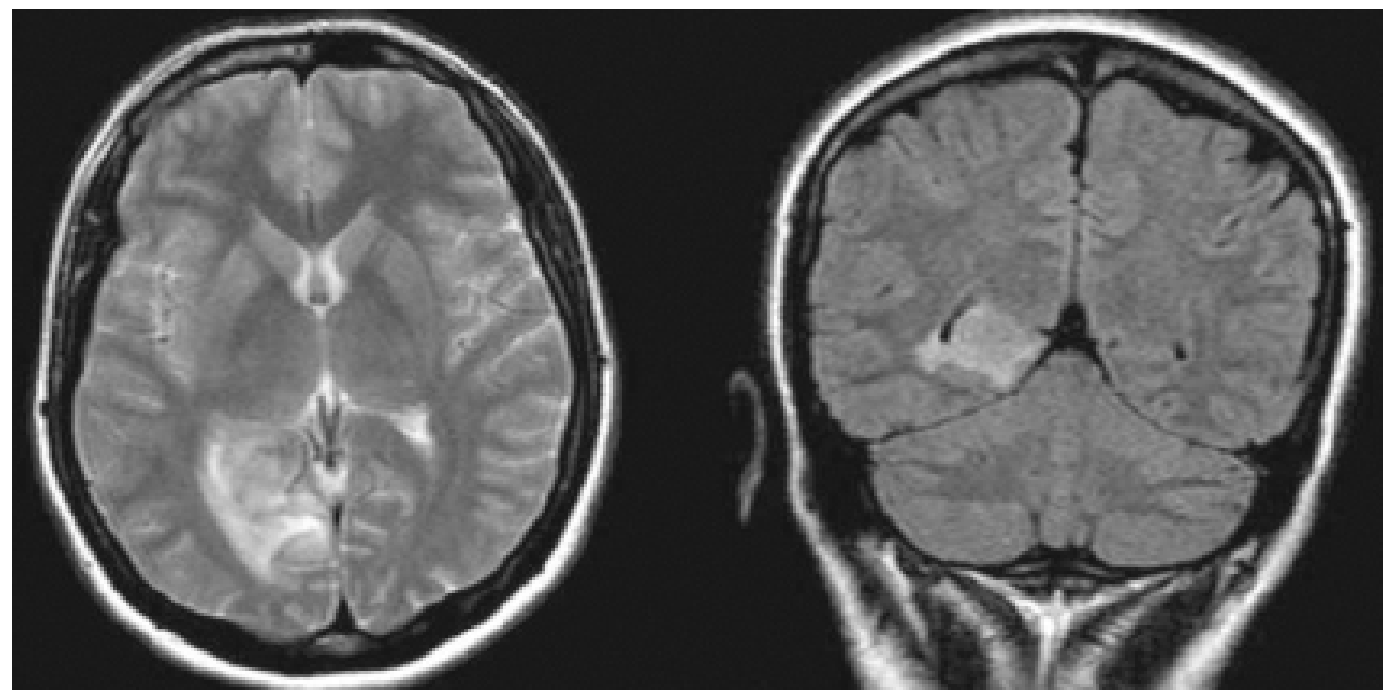

Figure 2. T2-weighted, axial, and fluid-attenuated inversion recovery coronal magnetic resonance imaging scans showing a well-defined focal mass lesion in the right occipital lobe.

Case-2: A 33-year-old female was admitted with a new-onset of episodic migraine-like visual aura for six months. The aura consisted of fortification spectra (expanding zigzag pattern) and transient flashing white lights always recurring in the left visual field followed by a moderate to severe left-sided throbbing headache several minutes later, although it did not always occur (acephalgic migraine with visual aura). Episodes of aura lasted minutes and were associated with nausea, vomiting, photophobia, and headache lasting several hours; relieved by sleep and oral analgesia. She had a positive family history, but no personal history of migraine. Her physical, neurological, and fundoscopic examination findings, including blood pressure and meningeal signs, were normal. Complete blood count and routine biochemistry results, including liver and renal function tests and erythrocyte sedimentation rate, were normal. Electroencephalography revealed normal findings. Cranial MRI revealed a large lesion with a mild contrast enhancement within the right occipital lobe, consistent with an astrocytoma (Fig. 2).

Case-3: A 23-year-old female was admitted with an increased frequency of headaches with visual aura for six months. The aura began as a star-shaped transient flashing white lights always recurring in the right visual field and, then, triangular zigzag lines followed by a moderate to severe left-sided throbbing headache several minutes later. Episodes of aura lasted minutes and were associated with nausea, photophobia, and headache lasting several hours; 


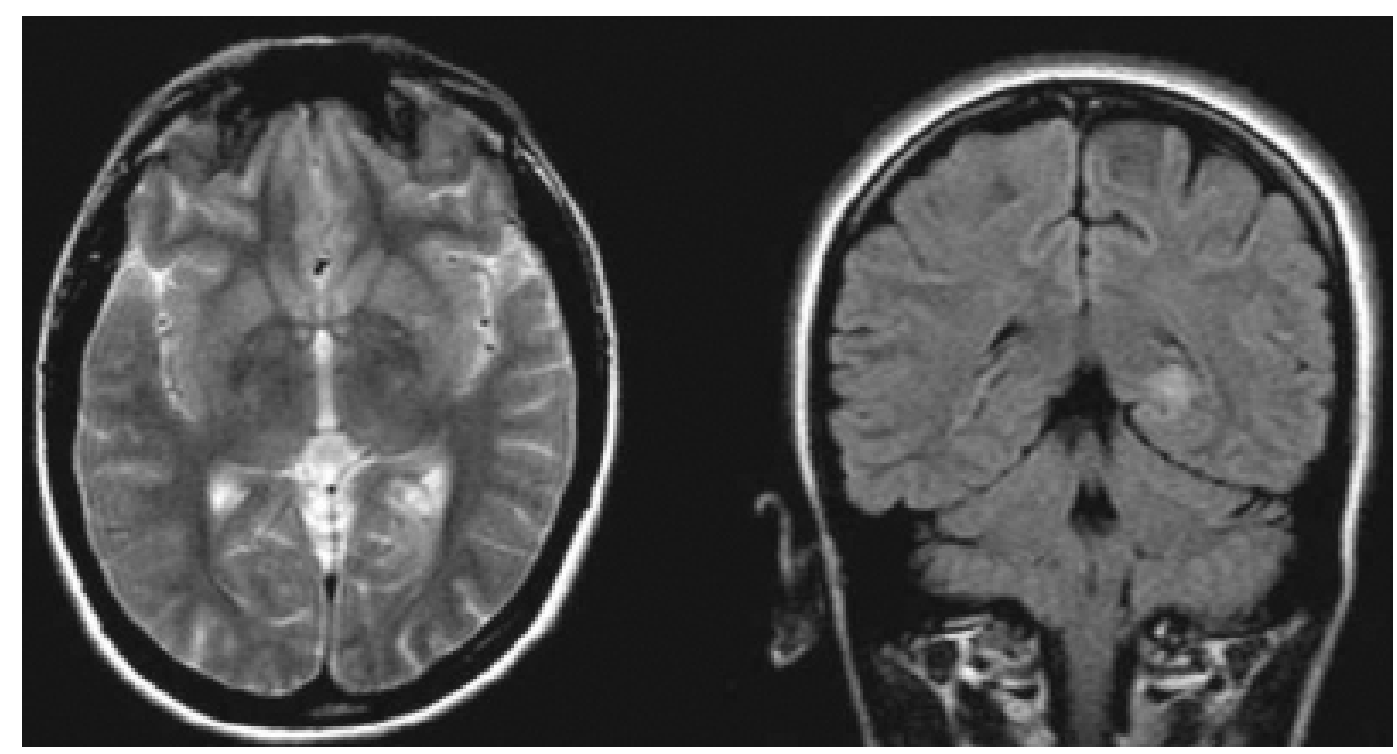

Figure 3. T2-weighted, axial, and fluid-attenuated inversion recovery coronal magnetic resonance imaging scans of a focal mass lesion in the right occipital lobe.

relieved by sleep and oral analgesia. There was no family or personal history of migraine. Her physical, neurological and fundoscopic examination findings, including blood pressure and meningeal signs, were normal. Complete blood count and routine biochemistry results, including liver and renal function tests and erythrocyte sedimentation rate, were normal. Electroencephalography revealed normal findings. Cranial MRI revealed a lesion without any contrast enhancement within the left occipital lobe, consistent with a low-grade astrocytoma (Fig. 3).

\section{Discussion}

A careful history and physical examination still remain the mainstays of headache assessment. Although a very low number of patients with headaches have brain tumors, recognition of tumor-associated headaches is of utmost importance. In a study including 85 patients with a brain tumor, Schankin et al. ${ }^{[4]}$ examined the characteristics of brain tumor-associated headache. The authors found that headache was the sole symptom in only $2 \%$. In another study, Forsyth et al. ${ }^{[5]}$ reported that headaches were similar to tension-type in $77 \%$, migraine-type in $9 \%$, and other types in $14 \%$ of 111 patients with a brain tumor. Our cases presented with only migraine-type headache with migraine-like visual aura due to an astrocytoma.

Furthermore, to critically examine the true nature of visual aura secondary to structural lesions and compare them to those of migraine, we examined three cases presenting with migraine-like visual aura caused by focal cerebral lesions. Neuronal hyperexcitability or cortical spreading depression can explain the comorbidity of disorders, such as migraine, epilepsy and acquired brain lesions, the overlap in clinical features, particularly visual aura. ${ }^{[2,6]}$ This mechanism may explain the discorelation between the localization of structural lesion and visual aura. Diagnostic criteria for typical migraine visual aura are shown in Table 1. ${ }^{[7]}$ Our cases experienced visual aura fulfilling the diagnostic criteria for migraine.

Considering the common features of these three cases (Table 2); one of them was increased frequency or new-onset of visual aura. All cases had typical visual aura with varying disease duration. Brief visual aura for seconds or less than five minutes was seen. The diagnostic criteria for migraine with aura stipulate that the aura symptoms develop gradually over 5 or more minutes and last no more than 60 minutes. ${ }^{[7]}$ Our experience however suggests that visual aura caused by cerebral lesions cannot be reliably differentiated from migraine on the basis of the duration of the aura. The other was changing in the characteristics of visual aura; such as repetitive flashes or transient flashing white lights with fortification spectra. The last one was the visual aura without headache. Based on the literature review on migraine-like visual aura due to focal cerebral lesions, the red-flag warning features of the visual aura include stereotypical visual aura, increasing frequency of visual aura, altered patterns or characteristics of chronic visual aura, any unexplained visual field defects, and nega- 
Table 1. Diagnostic criteria for typical migraine visual aura

I. At least two attacks fulfilling criteria II-IV

II. Aura consisting of at least one of the following, but no motor weakness

A. Fully reversible visual symptoms including positive features (e.g., flickering lights, spots, or lines) and/or negative features (i.e., loss of vision)

B. Fully reversible sensory symptoms including positive features (i.e., pins and needles) and/or negative features

(i.e., numbness)

C. Fully reversible dysphasic speech disturbance

III. At least two of the following

A. Homonymous visual symptoms and/or unilateral sensory symptoms

B. At least one aura symptom develops gradually over $\geq 5$ minutes and/or different aura symptoms occur in succession over $\geq 5$ minutes

C. Each symptom lasts $\geq 5$ and $\leq 60$ minutes

IV. Headache begins during the aura or follows aura within 60 minutes

V. Not attributed to another disorder

*International Classification of Headache Disorders (ICHD).

Table 2. Characteristics of three patients with an astrocytoma and the astrocytoma case reported initially

\begin{tabular}{lcccc}
\hline & Case 1 & Case 2 & Case 3 & Case from the literature $^{\mathbf{3}}$ \\
\hline Age (years) & 32 & 33 & 23 & 31 \\
New onset or old aura & Old & New & Old & New \\
Duration of aura (minutes) & 2 & 15 & 15 & 15 \\
Change in frequency of aura & Increase & Increase & Increase & Increase \\
Location of visual aura in visual field & Right & Left & Right & Bilateral \\
Location of headache & Right & Left & Left & Left sided \\
Location of lesion & Right frontal & Right occipital & Left occipital & Left temporal \\
Headache associated with aura & Yes & Yes & Yes & Yes \\
History of seizure & & (Not always) & & No \\
\hline
\end{tabular}

tive visual phenomena or subjective persistence of a scotoma following a typical visual aura. ${ }^{[2]}$

In conclusion, these cases highlight the importance of being aware that migraine-like visual aura may lead to the diagnosis of a brain structural lesion.

The study has complied with the principles of the Declaration of Helsinki.

\section{Conflict-of-interest issues regarding the author- ship or article: None declared.}

\section{Peer-rewiew: Externally peer-reviewed.}

\section{References}

1. Russell MB, Olesen J. A nosographic analysis of the migraine aura in a general population. Brain 1996;119(Pt 2):355-61.

2. Shams PN, Plant GT. Migraine-like visual aura due to focal cerebral lesions: case series and review. Surv Ophthalmol 2011;56(6):135-61. [CrossRef]

3. Magrotti E, Frascaroli G, Mariani G. Left temporal glioma presenting as migraine with typical aura. Ital J Neurol Sci 1992;13(5):444. [CrossRef]

4. Schankin CJ, Ferrari U, Reinisch VM, Birnbaum T, Goldbrunner R, Straube A. Characteristics of brain tumour-associated headache. Cephalalgia 2007;27(8):904-11. [CrossRef]

5. Forsyth PA, Posner JB. Headaches in patients with brain tumors: a study of 111 patients. Neurology 1993;43(9):1678-83.

6. Vincent MB. Vision and migraine. Headache 2015;55(4):595-9.

7. Headache Classification Subcommittee of the International Headache Society. The international classification of headache disorders: 2nd. Cephalalgia 2004;24:1-160. 